\title{
Cost Optimisation for Minimizing the Visual Impact of Ornamental Stone Quarrying. A Case Study in Murcia Region
}

\author{
José Molina-Ruiz ${ }^{1}$, María José Martínez-Sánchez², Carmen Pérez-Sirvent ${ }^{2}$, \\ Mari Luz García-Lorenzo ${ }^{3 *}$, María Luz Tudela-Serrano ${ }^{{ }^{*}}$ \\ ${ }^{1}$ Department of Geography, Faculty of Geography, University of Murcia, Campus de la Merced, Murcia, Spain \\ ${ }^{2}$ Department of Agricultural Chemistry, Geology and Pedology, Faculty of Chemistry, University of Murcia, Campus de Espinardo, \\ Murcia, Spain \\ ${ }^{3}$ Department of Mineralogy and Petrology, Faculty of Geology, University Complutense of Madrid, Madrid, Spain \\ Email: jmolinar@um.es, mjose@um.es, melita@um.es, *mglorenzo@geo.ucm.es, ^mltudela@um.es
}

How to cite this paper: Molina-Ruiz, J., Martínez-Sánchez, M.J., Pérez-Sirvent, C., García-Lorenzo, M.L. and Tudela-Serrano, M.L. (2018) Cost Optimisation for Minimizing the Visual Impact of Ornamental Stone Quarrying. A Case Study in Murcia Region. Journal of Geoscience and Environment Protection, 6, 74-88. https://doi.org/10.4236/gep.2018.62006

Received: November 13, 2017 Accepted: February 25, 2018 Published: February 28, 2018

Copyright (c) 2018 by authors and Scientific Research Publishing Inc. This work is licensed under the Creative Commons Attribution International License (CC BY 4.0).

http://creativecommons.org/licenses/by/4.0/

\begin{abstract}
Quarrying of ornamental stone has adverse effects that are both visual and environmental. This paper aims to develop a methodology for minimising the costs associated with reducing the visual impact of ornamental stone quarrying. This study uses digital topographical maps of the study zone and a GPS and GIS application to calculate the extent of the area affected by quarrying activities for each altitude designated in the work plan and to calculate the extent of the potential visual impact. The results obtained applying the proposed methodology for the selected area suggested that the potential visual impact is minimal for an altitude of 520 metres, this being the optimal point for the observer. When altitude increases, the potential visual impact increases and the optimal point for the observer diminishes until the highest impact altitude $(740 \mathrm{~m})$ is readied. The optimal point that the exploitation should reach is that at which the values of the diagram generated by the (\%) area of potential visual impact and area of exploitation (\%) intersect. The methodology allows the optimal altitude to be determined for mining exploitations and helps assess the viability of a given exploitation from an environmental point of view.
\end{abstract}

\section{Keywords}

Restoration Costs, Ornamental Stone, Visual Impact, Limestone, Quarrying

\section{Introduction}

Natural stone quarrying is a long established industry which, like many others, is 
undergoing a transformation as a result of the international economic climate.

The natural stone sector was severely affected by the construction sector crisis. Production, both ex works and processed, has been also harshly affected dropping from $8 \mathrm{Mt} / \mathrm{y}$ in 2007 to $3.49 \mathrm{Mt} / \mathrm{y}$ in 2015, particularly in the marble and granite sectors, since slate has always been a mainly exporting sub-sector. In the latest times, thanks mainly to exports, production apparently has slowly started to recover.

Spain, with an overall natural stone production of 3.49 Mt (2015), is currently the $7^{\text {th }}$ stone world producer, after China, India and Iran-who have recently emerged as main global producers-Turkey, Italy and Brazil. By sectors, marble and limestone marble represented $61 \%$ of the production, granite $19 \%$, roofing slate $19 \%$ and other stones $1 \%$. Roofing slate has suffered less the crisis thanks to the fact that it is mainly an exporting sector. The number of quarries has slightly reduced in the last few years, but the main stone processing centres (around 750) have survived the turmoil of the crisis by reducing production and engaging in an important international trade campaign. Spain exported, in 2013, $1.6 \mathrm{Mt}$ (1.35 Mt in 2014) of marble (more than $76 \%$ of the production) and $70 \%$ of the production of granite. Slate, a traditionally exporting sector, maintained exports in around $80 \%$ of the total production [1] [2].

The increased competition from these mega-producing countries, the appearance of new, competitively priced products and the construction crisis have led countries like Spain to change their outlook and to become world leaders in the research and development of new technologies applicable to ornamental stone sector. However, besides facing competition from these new producers, the European stone quarrying industry also has to apply rigorous environmental impact laws, which, among other demands, oblige companies to restore abandoned mining land. The growing competition from abroad, EU environmental demands and the inevitable economic implications mean that it is of enormous importance to know, from the initial stages of exploitation, the optimal design for minimising subsequent restoration costs, in an attempt to remain competitive on the world stage.

Land rehabilitation is an essential part of mining and quarrying, and could be defined as human involvement for removing the damage caused by quarries, in order to enable new land uses [3] [4]. Mining is a temporary form of land use, and the end of the exploitation has to be subjected to a careful planning, considering future land use options [5] [6]. Ornamental stone quarrying usually takes place on hill slopes using open-pit methods, where bedrock is cut. The quarry face progressively expands into the hill, growing in width and height, while terraces are formed during the quarrying process [7]. These activities produce significant alterations in land morphology, water, soil, vegetation and fauna [8] [9]. For this reason, visual impact evaluation is an important component of environmental analysis for landscape projects, since the resulting visual impact is one of the most important consequences of quarrying [10] [11]. 
Mining activities could be associated with sustainable development if site rehabilitation and remediation is considered before the exploitation starts. In Spain, the first legislation appeared in 1982, and, since then, mining projects must be accompanied by a mandatory Restoration Plan [12].

European Directive 2006/21/EC [13] demands the rehabilitation of areas in which mining has been practised, as did the already existing Spanish Mining Law (22/1973) [14] and as does more recent legislation (Royal Decree 975/2009) [15] on the management of wastes from the extractive industry and the protection and rehabilitation of the space affected by mining activities. This decree proposes that the post-mining conditions of land stability and usage have to be comparable to those that existed before the exploitation. Reclamation concerns include stabilization and the vegetation of disturbed lands, controlling drainage from portals and rubble, the neutralization or removal of process solutions and restoration of the visual landscape. Article 42 of this decree mentions that "calculation of the financial guarantee will take into account the environmental impact of the mining activities", in agreement with the European directive.

All the above should be considered in the light of section 24 of the Johannesburg Plan of Implementation on Sustainable Development [16], which focuses on the protection of natural resources. According to the plan, it is necessary to protect the natural resources that are the basis of economic and social development and to reverse the current trend towards the degradation of such natural resources, and to manage the same in a sustainable and integrated way.

Environmental planning in relation to open-cast mining was developed as a consequence of the evident need to make the profitable exploitation of geological resources compatible with environmental protection by studying land use in areas suited to the activity [17]. Nowadays, the location of the resource (cost) and profitability of the same (benefit) are not the only factors that must be considered, but also the compatibility of any activity with the environment. This determines the limits for the activity (threshold) based on the potential of regional landscapes and the territorial and environmental legislation as regards prevention and correction of negative impacts.

The environmental vacuum in the mining sector underlines the need for an initial design that minimises the impact of each development stage of an ornamental stone exploitation and that balances the activity and environment protection.

Four stages can be established in the design of a mining exploitation (Figure 1):

Stage 1: Study of the technical and environmental conditions of the potential area.

Stage 2: Mining exploitation.

Stage 3: Restoration work during exploitation phase and after abandoning the activity.

Stage 4: Re-use of the area for traditional activities. 
Mining activities often produce a visual impact, such as the opening of quarry pits, modification the zone's morphology, geometric forms of wastes generated, that contrast with the natural landscape and infrastructure construction (roads, electrical power lines, reservoirs, temporary buildings, etc.). The visual impact of open-cast mining activities in the ornamental stone sector is one of the most significant alterations and probably the main cause of its rejection by local populations (Figure 2).

Phase 1: Preoperational
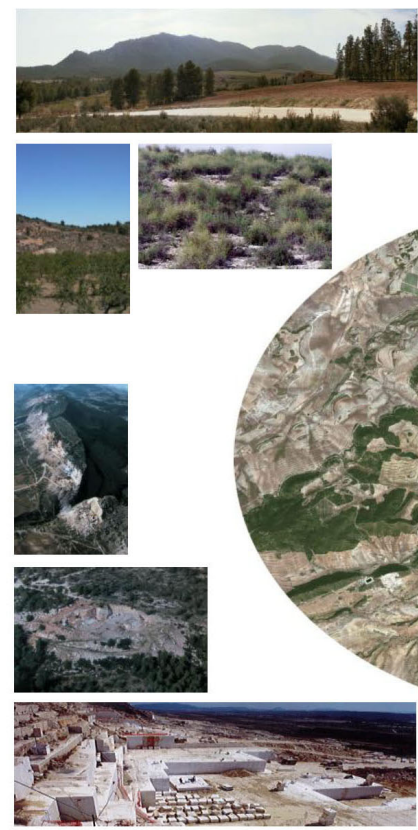

Phase 2: Exploitation

\section{Phase 4: Reutilization}
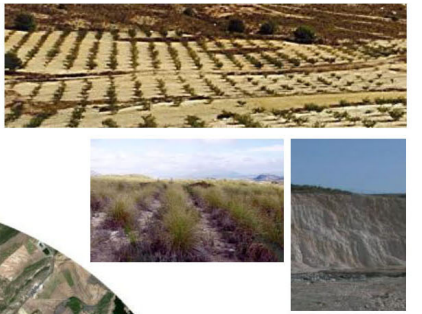

Figure 1. Planning an ornamental stone exploitation.

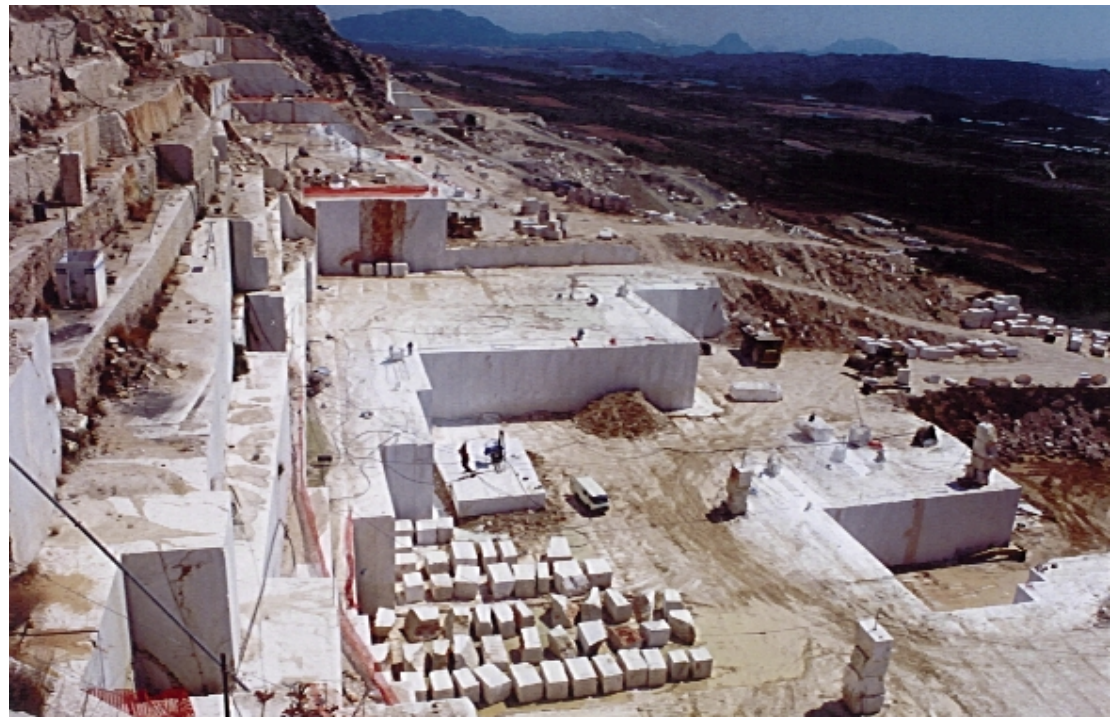

Figure 2. View of an ornamental stone exploitation in the studied area. 
The aim of this work was to develop a methodology to predict and evaluate the visual impact of open cast mining activities before the exploitation phase in an attempt to minimise the environmental impact and optimize the cost of restoration.

\section{Material and Methods}

\subsection{Study Area}

The case study presented in the paper takes place in Murcia Region (SE, Spain), in the locality of Cehegín. This area was chosen to study potential visual impacts produced as a consequence of mining activities, because contains the largest number of open cast mining exploitations in the province of Murcia (Figure 3). The area comprises a mountain range which combines abrupt slopes and ravines with areas a flat slope, all of them of a carbonated nature.

\subsection{Applied Methodology}

This study uses digital topographical maps of the study zone and a GPS and GIS application to calculate the extent of the area affected by quarrying activities for each altitude designated in the work plan and to calculate the extent of the potential visual impact. For this, ArcGis version 9.1 software was used. To achieve the detail necessary for this sort of study, a balance must be struck between work

\section{LEGEND}

- Ornamental stone exploitations in Murcia Region

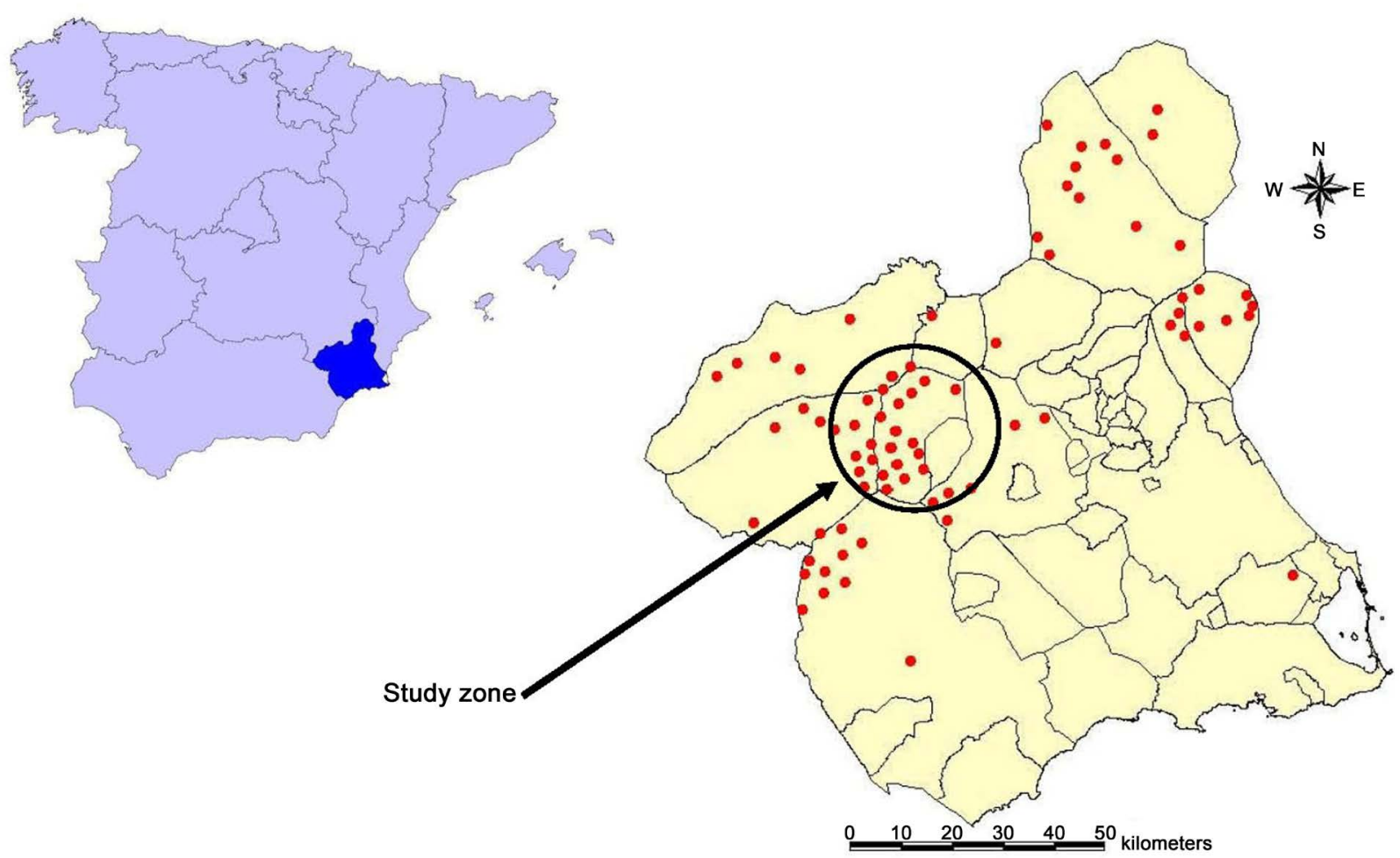

Figure 3. Spatial distribution of the ornamental stone quarries in the province of Murcia. 
scale, time and available resources.

The method was applied in three steps: i) Determination of the visual field; ii) Determination of potential visual impact as a function of the distance to the quarry; iii) Estimation of restoration costs.

The visual field is the area from which a given point is visible. The concept is related with the intervisibility term, which analyses a territory as a function of the degree of mutual visibility between different points within the territory. To determine the visual field, a digital model of elevations (DME) was constructed using a GIS. The visual fragility of the territory and visual acuity of the observer were also incorporated. According to Gerald Westheimer [18], the human eye has a visible minimum, given that the minimum visibility is the detection of the presence of a visual stimulus. Visual fragility could be defined as the susceptibility of a landscape to change when a given activity is carried out in it, in this case the quarrying of ornamental stone. From the visual basin values, information for evaluating the potential visual impact and restoration costs can be obtained.

The applied methodology to determine the potential visual impact and its influence on the cost of restoration is detailed as follows:

1) Construction of the Digital Elevation Model (DEM) of the study area.

2) Calculation of the radius of the visual basin as a function of observes visual acuity and the size of the observable object.

3) Establishment of reference points for constructing the visual basins, a number that varies as a function of the morphology of the study zone and taking into account the minimum and maximum altitudes of the exploitation [19].

4) Determination of areas of the visual basins and their sum, which corresponds to the maximum frequency of observation, the maximum visual fragility and the maximum visual impact [20].

5) Finally, determination of the areas affected and, as a function of the restoration costs, the exploitation design can be proposed.

\section{Results and Discussion}

\subsection{Determination of the Visual Basin}

The visual basin will depends on its radius and will be a function of the visual acuity of the observer and the size of the observable object. The human eye has a minimum visible, that is, minimum visibility is the detection of the presence of a visual stimulus (Adler, 1992). In a normal observer, with an optimum approach and a distance of $6 \mathrm{~m}$, the minimum angle of resolution is 1 arcminute, that is, $6 / 6$ or $20 / 20$, equivalent to $100 \%$ of visual acuity (Figure 4). At a distance of $6 \mathrm{~m}$ from an observation point, the minimum letter size is $8.73 \mathrm{~mm}$ (equivalent to 5 minutes of arc) and has an opening of $1.75 \mathrm{~mm}$ (equivalent to 1 arcminute). Then, the observation distance in the landscape ranges from $6 \mathrm{~m}$ to infinity. The arc length equivalent to 1 minute $(L)$ gives the observable object's size as a function of the distance $(d)$ in the following equation: 


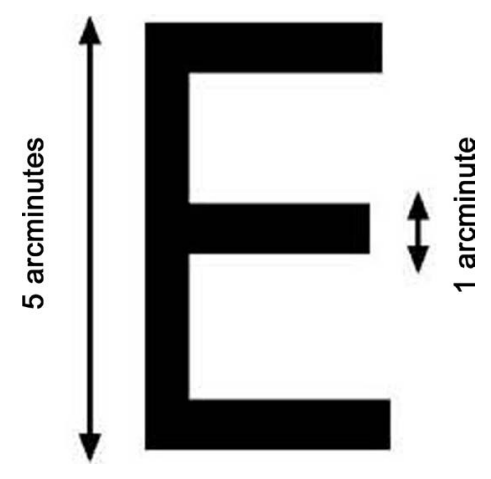

Figure 4. Snellen chart.

$$
L=\frac{\Pi}{180} \times \frac{1}{60} \times d
$$

Applying (1) and at a distance of 6 metres, the human eye does not differentiate objects smaller than $1.75 \mathrm{~mm}$.

In ornamental stone quarrying, the mean elevation of the pit face and auxiliary buildings is $2.90 \mathrm{~m}$. Substituting $L=2.90 \mathrm{~m}$ in (1), the distance at which the human eye can distinguish objects of this size is $10 \mathrm{~km}$. Therefore, $10 \mathrm{~km}$ is the radius for determining the visual basin of quarrying exploitations.

\subsection{Potential Visual Impact Determination as a Function of Distance from the Exploitation}

The potential visual impact is directly related with the visual fragility of the affected zone, which is related with the greatest observation frequency. That is, the more frequent the observation, the greater the impact on the landscape. When the reference points for calculating the visual basin area were chosen, potential observers (from roads, urban nuclei), the morphology of the study zone and minimum $(520 \mathrm{~m})$ and maximum $(740 \mathrm{~m})$ altitudes of the exploited pit faces were taken into account. The altitudinal gradient selected was $20 \mathrm{~m}$ (Table 1). Based on the established DEM in the study zone and taking into account the selected points, raster maps of the visual basins were constructed with a radius of $10 \mathrm{~km}$. The observer point of view is situated in the future exploitation, from where the visual basins are constructed. The resulting maps are summarised in Figure 5 and give an idea of the visual basin from each of the reference points. Analysis of these maps provides information on the areas potentially affected by visual impact and suggest that the greatest potential visual impact area corresponds to the highest point considered.

\subsection{Estimation of Restoration Costs}

A quarry has to be commercially viable and environmentally acceptable and for this reason, the visual impact is of great importance in the development of ornamental stone exploitations. In order to optimise the restoration costs it is essential to minimise the visual impact, and certain criteria need to be taken into 
Table 1. Relationship between the surface of the visual field and the potential visual impact.

\begin{tabular}{ccc}
\hline Point and altitude $\left(\right.$ mas $\left.^{*}\right)$ & Visual field surface (ha) & Visual impact increment $(\%)$ \\
\hline $1(520)$ & 162 & 0.00 \\
$2(540)$ & 1359 & 16.90 \\
$3(560)$ & 2523 & 20.56 \\
$4(580)$ & 3692 & 18.18 \\
$5(600)$ & 3692 & 0.00 \\
$6(620)$ & 3692 & 0.00 \\
$7(640)$ & 4779 & 16.93 \\
$8(660)$ & 4779 & 0.00 \\
$9(680)$ & 5435 & 10.19 \\
$10(700)$ & 5913 & 7.40 \\
$11(720)$ & 5913 & 0.00 \\
$12(740)$ & 6436 & 8.14 \\
\hline
\end{tabular}

$\left.{ }^{*}\right)$ metres above the sea level.

account: the maximum height of the pit face; the area covered by the exploitation and the area affected by visual impact $(10 \mathrm{~km})$. In our study and to estimate the restoration costs two cases were contemplated: the existence, or not, of obstacles between the observer and the affected zone.

\subsubsection{Case 1: Restoration Costs without Obstacles between the Observer and the Affected Area}

Figure 6 represents an observer facing a quarry a metres wide and $h$ metres high. Let us consider that a section of height $\Delta h$ and width $a$ has to be restored at a cost per $\mathrm{m}^{2}$ of P euros. $\Delta h=h_{1}-h$, where $h_{1}$ is the maximum height of the exploitation (difference between the maximum and minimum altitude) and $h$ is the height above which restoration must be carried out (difference between optimum altitude and minimum altitude of the exploitation). The cost of restoration $\left(X_{1}\right)$ is represented in Equation (2):

$$
X_{1}=(a \times \Delta h) P
$$

The restoration costs fall as $\Delta h$ decreases, fulfilling Equations ((3) and (4)):

$$
\begin{gathered}
\Delta h \leq \frac{X_{1}}{P \times a} \\
\left(h_{1}-h\right)=\frac{X_{1}}{P \times a}
\end{gathered}
$$

Equation (5) corresponds to a straight line with slope $\frac{-1}{P \times a}$ and ordinate origin $\left(h_{1}\right)$. The lower the amount of money available $\left(X_{1}\right)$ the larger the area that will not be restored. 


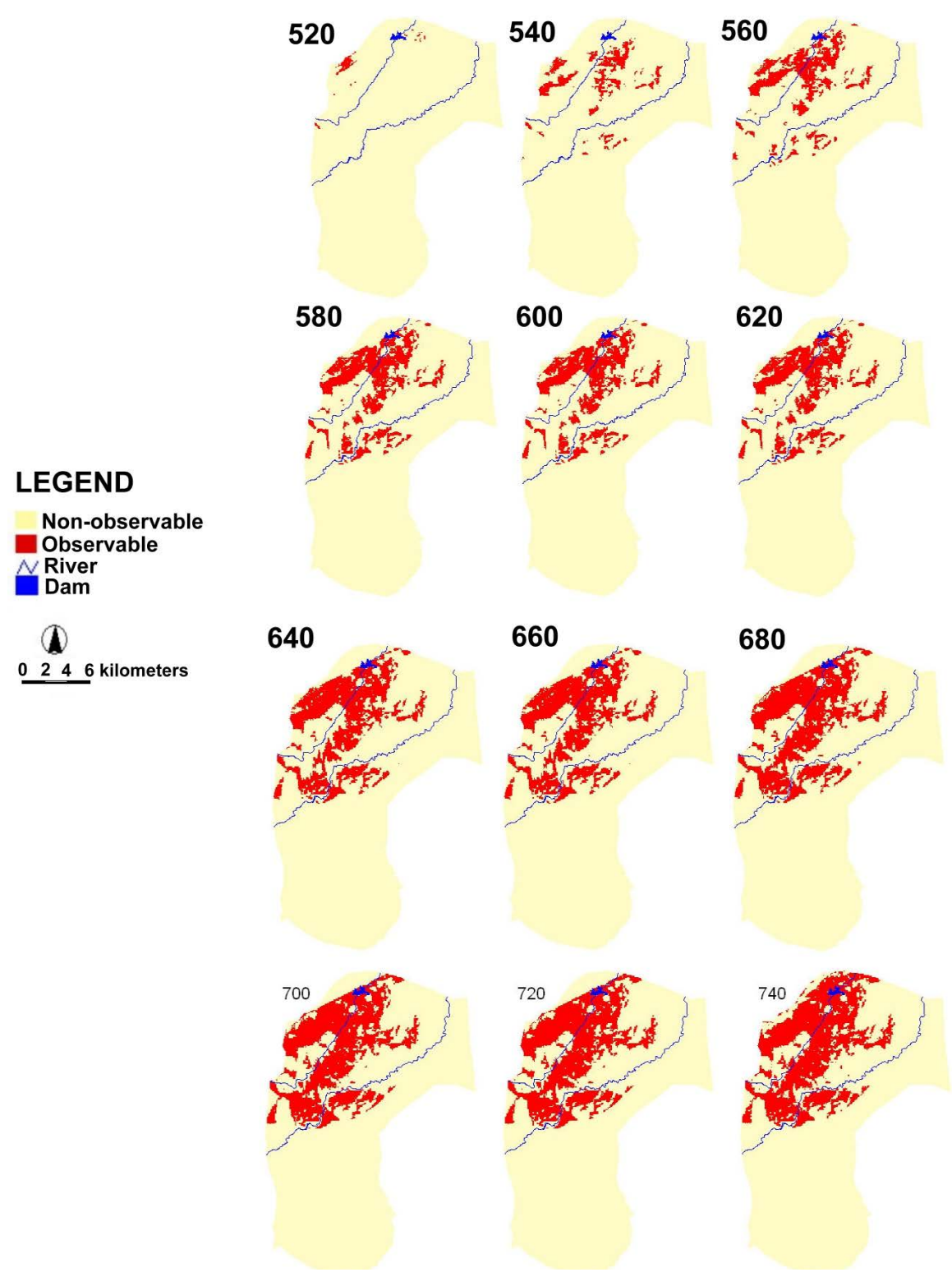

Figure 5. Observable and non-observable areas from 520 to $740 \mathrm{~m}$.

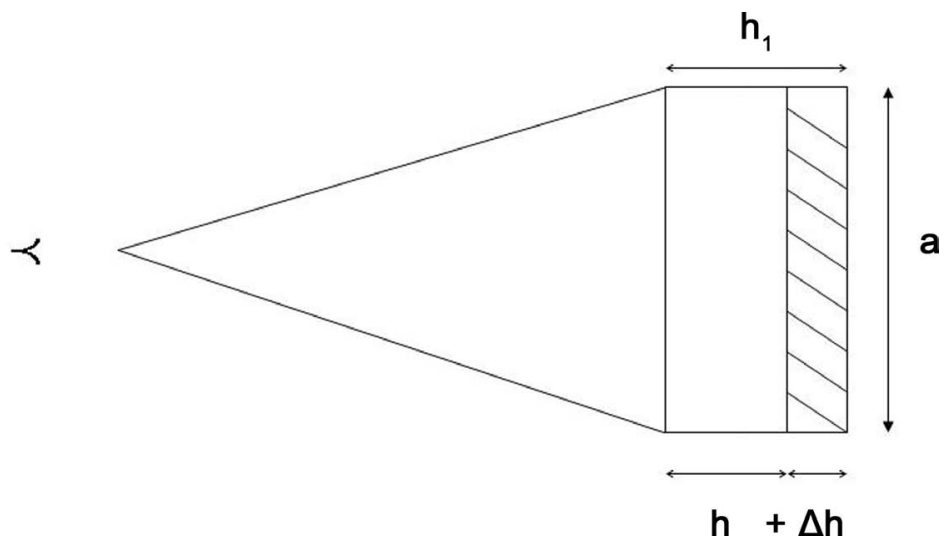

Figure 6. Restoration diagram for a visual field without obstacles. 


$$
h=h_{1}-\left(\frac{1}{P \times a}\right) \times X_{1}
$$

\subsubsection{Case 2: Restoration Costs with Obstacles or Hills} between the Observer and the Affected Area

The visibility between two points depends on the presence of obstacles such as hills, rocks, trees, houses or dunes. In the pre-operational phase, costs can be determined as a function of the visual impact (Equation (6)):

$$
S \times P=X(\text { potential })
$$

Figure 7 showed an observer facing the exploitation with an obstacle intervening. Consider that $C$ is the obstacle height; $d_{1}$ is the distance between the observer and the obstacle; $H$ is the height of the affected mountain range which cannot be observed because of the obstacle; $D$ is the distance between the observer and the affected area and $\Delta h$ is the height of the affected mountain range which can be observed. $\Delta h=h_{1}-h$, where $h_{1}$ is the maximum height of the exploitation (difference between maximum and minimum altitudes of the exploitation) and $h$ is the elevation up to which restoration must be carried out (difference between optimal altitude and minimum altitude of the exploitation).

If all the affected area is restored, $\Delta h=0, \alpha=\beta$ and $\operatorname{tg} \alpha=\operatorname{tg} \beta$ (Equation (7)):

$$
\begin{gathered}
\operatorname{tg} \alpha=\frac{C}{d_{1}}=\frac{H}{D} ; \operatorname{tg} \beta=\frac{h_{1}}{D} \\
\frac{C}{d_{1}}=\frac{h_{1}-\Delta h}{D}
\end{gathered}
$$

As the restoration costs are $X=(a \times \Delta h) \times P$, the optimal restoration cost will be (8). The ideal restoration costs are constant as a function of the distance to and height of the obstacles.

$$
X_{2}=\left(h_{1}-C \times \frac{D}{d_{1}}\right) \times P \times a
$$

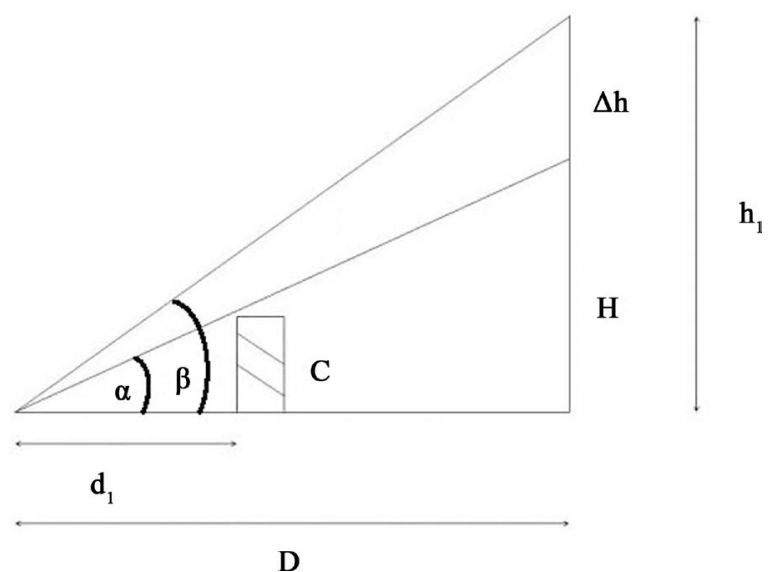

Figure 7. Restoration diagram for a visual field with obstacles. 


\subsection{Application to a Quarry in Cehegín}

Visual impact is a consequence of introducing new elements in the landscape. In our case, the greatest impact will be the quarry face and dumps in the hillside. This visual impact is directly related with the visual fragility of the affected zone, which, in turn, is related with the frequency of observation; that is, the greater the frequency, the greater the impact on the landscape. Observation frequency is related with topography, the presence of visual screens, population density, the dispersion of inhabited nuclei, the density of the communications network and the frequency of use. The distance at which any observation is made is also important. At less than $5 \mathrm{~km}$ distance, the perception of alterations in the landscape is usually very strong. The impression is usually negative because of the extreme nature of the contrast with the surroundings as result of moving earth, opening excavations, the presence of auxiliary buildings, etc. Movement through interior visual basins is usually slow since journeys are generally made along mountain roads and unsurfaced tracks, which increases the observation time. The impact will be directly proportional to the intensity of public use of the zone, the road network and its quality, as well as to the protective frameworks present in the affected spaces. At a medium distance $(5-10 \mathrm{~km})$ the perception of landscape alteration is also strong. Observations are usually made from roads outside the immediate centre of alteration and the observation time is usually shorter because the roads are better and faster, and the topography may interrupt the view more frequently. The affected area can also be observed from isolated houses of population centres if the topography does not intervene, and the impression is usually negative since the exploitation is regarded as an aggression against the normal state of the landscape.

At distances from 10 to $50 \mathrm{~km}$ only a slight modification of the background tonality is perceived, from roads, individual dwellings or urban centres. This perception is not necessarily negative and diminishes as the distance increases.

Based on the above considerations, we have constructed visual basins for a radius of $10 \mathrm{~km}$, considering that the main visual impacts are: i) alterations of the landscape background as a result of excavations and topographic alterations; ii) new elements in the landscape such as roads, dumps, auxiliary buildings, etc., some of them producing sharp contrasts with the landscape.

The visually impacted area (Table 2) gradually increases as elevation rises, especially in the first $100 \mathrm{~m}$. An observer situated at the lowest reference point will see a small area of the total visual basin since their line of vision will be interrupted by the land morphology. From higher observation points, the visible area increases gradually until the average altitude is reached. Above this elevation, the natural obstacles diminish in size and the percentage of visible surface is increased. At higher elevations, the increase in the percentage of visible area slows down until the greatest possible area is observed, representing the strongest visual impact.

Previous theoretical demonstration allows the optimal altitude for the work 
Table 2. Relationship between visual field surface and exploitation surface.

\begin{tabular}{cccc}
\hline $\begin{array}{c}\text { Point and } \\
\left.\text { altitude (mas }{ }^{\star}\right)\end{array}$ & $\begin{array}{c}\text { Exploitation } \\
\text { surface } \%\end{array}$ & $\begin{array}{c}\text { Exploitation } \\
\text { surface (ha) }\end{array}$ & $\begin{array}{c}\text { Potential impact } \\
\text { surface (\%) }\end{array}$ \\
\hline $1(520)$ & 100 & 90.86 & 2.51 \\
$2(540)$ & 76.65 & 69.95 & 21.11 \\
$3(560)$ & 63.43 & 57.64 & 39.16 \\
$4(580)$ & 52.54 & 47.74 & 57.34 \\
$5(600)$ & 41.55 & 37.76 & 57.34 \\
$6(620)$ & 33.20 & 30.17 & 57.34 \\
$7(640)$ & 23.85 & 21.67 & 74.27 \\
$8(660)$ & 16.82 & 15.29 & 74.27 \\
$9(680)$ & 10.16 & 9.23 & 84.46 \\
$10(700)$ & 5.19 & 4.72 & 91.86 \\
$11(720)$ & 2.06 & 1.87 & 91.86 \\
$12(740)$ & 0.22 & 0.20 & 100 \\
\hline
\end{tabular}

$\left.{ }^{*}\right)$ metres above the sea level.

plan to be calculated. This is a useful tool for knowing, in the pre-operational phase, the magnitude of the impact by comparing restoration costs. This aspect must be taken into account during the planning stage to determine whether the exploitation is viable from an economic and environmental point of view. An important issue, during the optimization of restoration costs, is to know precisely the extent of the affected area for each altitude. Knowing this, it is possible to check the possible relationship between the size of the restored area and the diminution of the potential visual impact. For this aim, the work plan, topographical maps (1:5000) and GPS measurements could be used. Then, it is possible to calculate the area affected by mining activities for each altitude and the results can be expressed as \% in order to better illustrate how the affected surface increases with altitude.

The results obtained for the selected area suggested that the potential visual impact is minimal for an altitude of $520 \mathrm{~m}$, this being the optimal point for the observer. When altitude increases, the potential visual impact increases and the optimal point for the observer diminish until the highest impact altitude $(740 \mathrm{~m})$ is readied. The optimal point that the exploitation should reach is that at which the values of the diagram generated by the (\%) area of potential visual impact and area of exploitation (\%) intersect, that is, up to the altitude at which the relation between the exploitation area and the visual impact generated is considered acceptable.

The relation between the diminution of the visual impact and the investment necessary is shown in Figure 8, allowing the optimal altitude that an exploitation can reach without producing an excessive visual impact to be defined. The optimal point of exploitation is the intersection of the two variables. Below this 


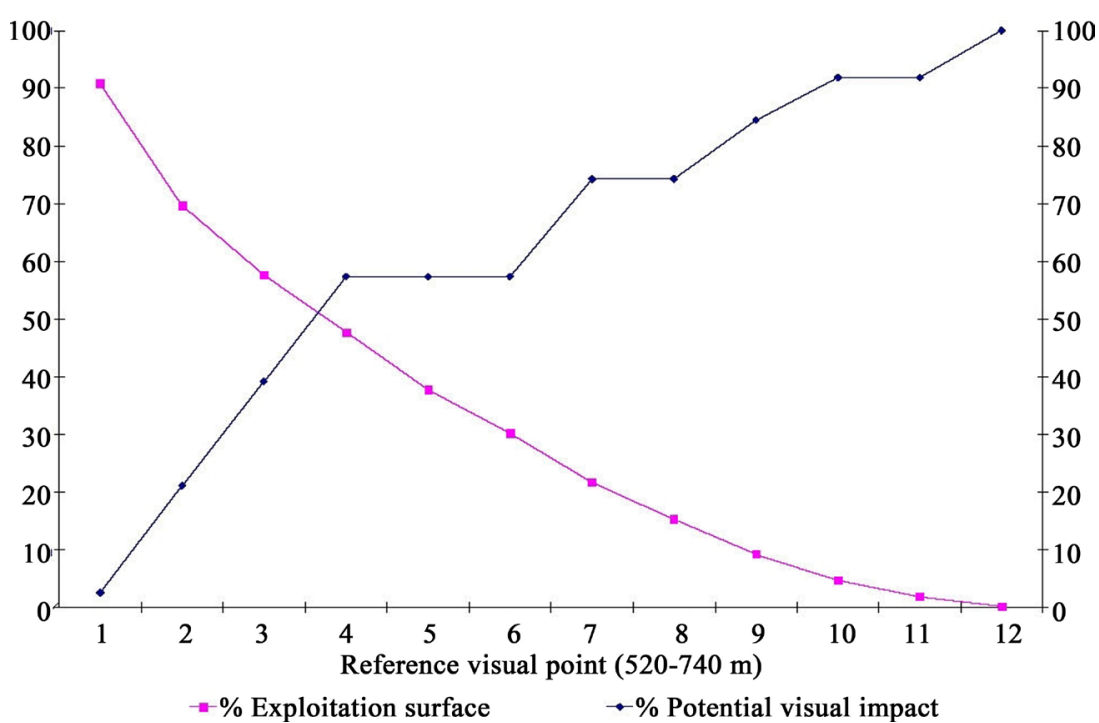

Figure 8. Relationship between the surface of visual impact and exploitation surface curves.

point the exploited area is greater (greater production), this area corresponding to a smaller visual basin and acceptable potential visual impact. Above this optimal point, the exploited area diminishes as the altitude increases, accompanied by growing visual impact, meaning that the financial guarantees needed for restoration increase.

\section{Conclusions}

The proposed methodology could be summarised as follows: 1) Determination of the potential visual field as a function of the visual acuity of observers; 2) Determination of the surface of the potential visual impact as a function of the altitude: considering the exploitation surface, the optimal point is the intersection point between the affected surface and the potential impact; 3) The optimal exploitation corresponds to the intersection between the exploitation surface and the potential visual impact.

The restoration costs are a function of the affected area and so, during the design (in the pre-operational stage) the input in the landscape can be minimized.

The proposed methodology could be a useful tool to assess in the planning stage of the exploitation, the varying of restoration costs and the magnitude of the potential visual impact, depending on the altitudinal position reached by the exploitation. In addition, the proposed methodology could help on the design phase to ensure the economic and environmental viability of mining activities according to European and national legislation, facilitating the task of decision makers.

\section{References}

[1] Marchán, C. and Regueiro, M. (2017) La piedra natural en España: Evolución y perspectivas Natural Stone in Spain: trends and perspectives. Boletín Geológico y 
Minero, 128, 395-403. https://doi.org/10.21701/bolgeomin.128.2.008

[2] OMPN, Market Observatory for Natural Stone (2012) Informe sectorial de la piedra natural en España 2012. AIDICO. http://www.aidico.es/

[3] Miao, Z. and Marrs, R. (2000) Ecological Restoration and Land Reclamation in Open-Cast Mines in Shanxi Province, China. Journal of Environmental Management, 59, 205-215. https://doi.org/10.1006/jema.2000.0353

[4] Milgrom, T. (2008) Environmental Aspects of Rehabilitating Abandoned Quarries: Israel as a Case Study. Landscape and Urban Planning, 87, 172-179.

https://doi.org/10.1016/j.landurbplan.2008.06.007

[5] Neri, A.C. and Sánchez, L.E. (2010) A Procedure to Evaluate Environmental Rehabilitation in Limestone Quarries. Journal of Environmental Management, 91, 2225-2237. https://doi.org/10.1016/j.jenvman.2010.06.005

[6] Svobodova, K., Sklenicka, P., Molnarova, K. and Salek, M. (2012) Visual Preferences for Physical Attributes of Mining and Post-Mining Landscapes with Respect to the Sociodemographic Characteristics of Respondents. Ecological Engineering, 43, 34-44. https://doi.org/10.1016/j.ecoleng.2011.08.007

[7] Mouflis, G.D., Gitas, I.Z., Iliadou, S. and Mitri, G.H. (2008) Assessment of the Visual Impact of Marble Quarry Expansion (1984-2000) on the Landscape of Thasos island, NE Greece. Landscape and Urban Planning, 86, 92-102.

https://doi.org/10.1016/j.landurbplan.2007.12.009

[8] Phillips, J. (2012) Applying a Mathematical Model of Sustainability to the Rapid Impact Assessment Matrix Evaluation of the Coal Mining Tailings Dumps in the Jiului Valley, Romania. Resources, Conservation and Recycling, 63, 17-25. https://doi.org/10.1016/j.resconrec.2012.03.003

[9] Prieto, B., Silva, B. and Aira, N. (2006) Methodological Aspects of the Induction of Biofilms for Remediation of the Visual Impact Generated by Quartz Mining. Science of the Total Environment, 370, 254-261. https://doi.org/10.1016/j.scitotenv.2006.07.030

[10] Menegaki, M.E. and Kaliampakos, D.C. (2012) Evaluating Mining Landscape: A Step Forward. Ecological Engineering, 43, 26-33. https://doi.org/10.1016/j.ecoleng.2011.02.011

[11] Sansoni, C. (1996) Visual Analysis: A New Probabilistic Technique to Determine Landscape Visibility. Computer-Aided Design, 28, 289-299.

https://doi.org/10.1016/0010-4485(95)00038-0

[12] Martín-Duque, J.F.M., Pedraza, J., Díez, A., Sanz, M.A. and Carrasco, R.M. (1998) A Geomorphological Design for the Rehabilitation of an Abandoned Sand Quarry in Central Spain. Landscape and Urban Planning, 42, 1-14. https://doi.org/10.1016/S0169-2046(98)00070-X

[13] European Commission (2006) Directive 2006/21/EC of the European Parliament and of the Council of 15 March 2006 on the Management of Waste from Extractive Industries and Amending Directive 2004/35/EC.

[14] Spanish Law 22/1973 of July 21, of Mines.

[15] Spanish Royal Decree 975/2009 of 12 June, on the Management of Wastes from the Extractive Industries and the Protection and Rehabilitation of Areas Affected by Mining Activities.

[16] United Nations (2002) Plan of Implementation of the World Summit on Sustainable Development. Report of the World Summit on Sustainable Development, Johannesburg, A/CONF.199/20, United Nations, New York. 
[17] Degan, G.A., Lippiello, D., Picciolo, L. and Pinzari, M. (2014) Visual Impact from Quarrying Activities: A Case Study for Planning the Residential Development of Surrounding Areas. WIT Transactions on Ecology and the Environment, 181, 125-135. https://doi.org/10.2495/EID140111

[18] Adler, F.H. and Hart, M. (1992) Adler's Physiology of the Eye: Clinical Application. Mosby Year Book, St. Louis.

[19] Molina-Ruiz, J. (2000) Minimización de impactos ambientales en la minería de la roca ornamental de la Región de Murcia. Doctoral Thesis, University of Murcia, Murcia.

[20] Molina-Ruiz, J., Martínez-Sánchez, M.J., Pérez-Sirvent, C., Tudela-Serrano, M.L. and García-Lorenzo, M.L. (2011) Developing and Applying a GIS-Assisted Approach to Evaluate Visual Impact in Wind Farms. Renewable Energy, 36 1125-1132. https://doi.org/10.1016/j.renene.2010.08.041 